\title{
Analisis Dampak Positif terhadap Kesejahteraan dan Pertumbuhan Ekonomi dalam Penerapan Konsep Desa Wisata di Desa Batulayang, Kabupaten Bogor
}

\author{
Yudhiet Fajar Dewantara ${ }^{1 \mathrm{a} *}$, Prayogo Susanto ${ }^{2 \mathrm{~b}}$ \\ ${ }^{\text {a }}$ Prodi Hospitality dan Pariwisata - Universitas Bunda Mulia \\ ${ }^{\mathrm{b}}$ Prodi Hospitality dan Pariwisata - Universitas Bunda Mulia \\ 1ydewantara@bundamulia.ac.id,22psusanto@bundamulia.ac.id \\ *corresponding author
}

ARTICLE INFO

Article history

Received

Revised

Accepted

Keywords

Tourist Village, Foreign Exchange

Earnings, Contributions to Government

Revenues, Employment Generation,

Development of Local Economies.

\begin{abstract}
In 2013 village Batulayang subdistrick Cisarua, distric Bogor West Java into tourist village because dates from outbound managed by the local people. The purpose of this research objectives is to determine the positive impact on welfare and economic growth with the application of the concept of tourist village in the village Batulayang, Bogor Districts, West Java. Research methods that were used to the research is the quantitative methods with Cartesian used diagrams of evidence. In this research researchers uses a questionnaire that will be distributed to resident of the village of Batulayang. The result and the discussion in a quadrant I namely foreign exchange earnings having a high priority because if there are guests foreign tourists and experienced a lack of financial in rupiah, so foreign tourists can use the currencies of his country in cash and bank which is to use. In a quadrat II to, government revenues employment generation, and development of local economies in dimension which means the means the means to uphold are very important. In a quadrant III, no in other words no effect on economic growth. On quadrant IV infrastructure development in a quadrant is considered less important because tourists be preoccupied with activities in the village and the tourist will use smartphone, before going to sleep but to signal and electricity are adequate. The conclusions researchers is tourist village very helpful for the economy residents and can grow economy. As a suggestion the government can cooperate with Batulayang village and private sector to create artificial attraction in Batulayang village to build marketing in the village and increase a vacancy for local residents.
\end{abstract}

\section{Pendahuluan}

\subsection{Latar Belakang}

Destinasi Pariwisata sudah menjadi salah satu penyumbang devisa negara Indonesia yang di peroleh dari kunjungan wisata macanegara yang mampu meningkatkan dari segi perekonomian nasional serta pembangunan nasional. Devisa sektor pariwisata mengalami peningkatan dari tahun ke tahun. Peningkatan yang signifikan terjadi pada tahun $2017 \mathrm{ke}$ 2018 dengan selisih 4.05 Miliar US \$. Dengan adanya pendapatan devisa dari sektor pariwisata di Indonesia menimbulkan dampak positif lainnya, seperti membaiknya infrastruktur, menciptakan lapangan pekerjaan baru, peningkatan taraf hidup dan kesejahteraan masyarakat dan juga meningkatan berbagai industri, seperti industri kuliner, industri transportasi, industri perhotelan atau penginapan dan industri terkait lainnya.

Hal ini sesuai dengan pernyataan Menteri Keuangan RI, Sri Mulyani yang menyatakan bahwa sektor pariwisata memberikan dampak pengganda (multiplier effect) yang sangat besar, baik bagi perolehan devisa negara, maupun dari sisi penyerapan tenaga 
kerja menurut Fitriani dalam (Natalia, 2019). Menurut organisasi pariwisata dunia, World Tourism Organization (WTO) dalam Muljadi (2009, h9), yang dimaksud dengan pariwisata adalah berbagai aktivitas yang dilakukan orang-orang yang mengadakan perjalanan untuk dan tinggal di luar kebiasaan lingkungannya dan tidak lebih dari satu tahun berturut-turut untuk kesenangan, bisnis, dan keperluan lain.

Berdasarkan Undang-Undang No. 10 Tahun 2009 tentang Kepariwisataan, kepariwisataan adalah keseluruhan kegiatan yang terkait dengan pariwisata dan bersifat multidimensi serta multidisiplin yang muncul sebagai wujud kebutuhan setiap orang dan negara serta interaksi antara wisatawan dan masyarakat setempat, sesama wisatawan,memiliki beberapa hal untuk menimbang, seperti pada poin (b), yaitu bahwa kebebasan melakukan perjalanan dan memanfaatkan waktu luang dalam wujud berwisata merupakan bagian dari hak asasi manusia. Dan pada poin (c) menyatakan bahwa kepariwisataan merupakan bagian integral dari pembangunan nasional yang dilakukan secara sistematis, terencana, terpadu, berkelanjutan, dan bertanggung jawab dengan tetap memberikan perlindungan terhadap nilai-nilai agama, budaya yang hidup dalam masyarakat, kelestarian dan mutu lingkungan hidup, serta kepentingan nasional.

Menurut I. Pithana dalam (Hermawan, 2018) arti kata pariwisata bermula dari bahasa sang sekerta yang terdiri dari 2 kata yaitu "pari" yang artinya keliling atau bersama dan "wisata" yang artinya perjalanan. Tambahan Gamal Suwantoro dalam (Ucok Pargaulan Lubis, 2018:5) pariwisata dan pengertian pariwisata memiliki hubungan erat, yaitu suatu kegiatan berpindah tempat untuk sementara waktu dengan bertujuan untuk rekreasi atau mencari hiburan dan bukan suatu kegiatan bekerja atau mencari uang.

Di Indonesia, sektor pariwisata merupakan sektor yang penting dan menjadi fokus pemerintah, yakni baik Pemerintah Pusat maupun Pemerintah Daerah. Terutama Kementerian Pariwisata dan Ekonomi Kreatif terus berupaya meningkatkan sektor pariwisata di Indonesia. Selain Pemerintah Pusat, Pemerintah Daerah juga melakukan pengembangan pariwisata di daerahnya, termasuk Pemerintah Daerah Kabupaten Bogor, Jawa Barat.

Pariwisata Kabupaten Bogor terus mengalami kenaikan. Menurut informasi dari Kabupaten Bogor, daerah Bogor memiliki beberapa potensi wisata mulai dari wisata alam, wisata sejarah, wisata buatan, dan wisata religion. Hal yang menarik dari Bogor ialah memiliki beberapa destinasi wisata yang bermula dari sebuah desa yang kemudian menjadi desa wisata. Berikut dapat di lihat daftar daya tarik wisata yang berada dari sebuah desa di Kabupaten Bogor Jawa Barat :

Tabel 1.1

Desa Wisata Kabupaten Bogor

\begin{tabular}{|l|l|l|l|}
\hline No. & Desa Wisata & Kecamatan & Daya Tarik \\
\hline 1. & Tapos I & Tenjolaya & Alam dan sejarah \\
\hline 2. & Gunung Malang & Tenjolaya & $\begin{array}{l}\text { Alam, pertanian dan } \\
\text { kesenian }\end{array}$ \\
\hline 3. & Pasir Eurih & Tamansari & Alam dan kerajinan \\
\hline 4. & Tamansari & Tamansari & Pertanian dan kerajinan \\
\hline 5. & Sukajadi & Tamansari & Alam dan pertanian \\
\hline 6. & Gunungsari & Pamijahan & Alam dan pertanian \\
\hline 7. & Ciasihan & Pamijahan & Alam dan kesenian \\
\hline 8. & Cimande & Caringin & Alam, budaya, dan kerajinan \\
\hline 9. & Citapen & Ciawi & Pertanian dan peternakan \\
\hline 10. & Tugu Selatan & Cisarua & Alam dan kesenian \\
\hline 11. & Tugu Utara & Cisarua & Alam, pertanian dan budaya \\
\hline 12. & Batulayang & Cisarua & Alam, seni, dan budaya \\
\hline
\end{tabular}




\begin{tabular}{|l|l|l|l|}
\hline No. & Desa Wisata & Kecamatan & Daya Tarik \\
\hline 13. & Citeko & Cisarua & Alam dan pertanian \\
\hline 14. & Kopo & Cisarua & Pertanian dan kerajinan \\
\hline 15. & Leuwi Malang & Cisarua & Alam dan kuliner \\
\hline 16. & Ligarmukti & Kelapanunggal & Alam, goa dan pemandian \\
\hline 17. & Jampang & Kemang & Budaya dan kerajinan \\
\hline 18. & Gobang & Rumpin & Bdaya dan kerajinan \\
\hline 19. & Megamendung & Megamendung & Alam dan pertanian \\
\hline 20. & Sukaresmi & Megamendung & Alam dan pertanian \\
\hline 21. & Ciseeng & Ciseeng & Minawisata/perikanan \\
\hline 22. & Kiarasari & Sukajaya & Alam \\
\hline 23. & Tajur & Citeureup & Alam (goa) \\
\hline 24. & Tarikolot & Citeureup & Kerajinan \\
\hline 25. & Pasirmukti & Citeureup & Kerajinan \\
\hline 26. & Malasari & Nanggung & Alam, pertanian, kerajinan \\
\hline 27. & Cilember & Cisarua & Alam \\
\hline
\end{tabular}

Sumber : (Liliana Dewi, 2019: 51-51)

Wisatawan yang berada di kota akan merasa jenuh dan akan berpergian ke suatu tempat lain, bisa ke laut atau ke dataran tinggi (pegunungan). Wisatawab bisa juga bepergian dalam waktu kurun dekat (pulang-pergi) atau dalam kurun waktu panjang (berhari-hari). Hal ini membuat di Kabupaten Bogor bermuculan tempat penginapan baik berupa hotel ataupun homestay. Demikian pula dengan desa-desa yang ada di Kabupaten Bogor, mereka berlomba-lomba menjadikan desanya menjadi desa wisata.

Dari sekian desa wisata, sudah pasti memiliki ciri-ciri yang khas dan digemari oleh setiap wisatawan yang berkunjungm, salah satunya Desa Wisata Batulayang yang berlokasi di Desa Wisata Batulayang Jln.Sultan Hasanudin Kap.Pasir Manggis Batukasur RT 006/004 Desa Batulayang Kecamatan Cisarua Kabupaten Bogor, Jawa Barat. Tak hanya suasana perdesaannya saja yang menjadi incaran para wisatawan, tetapi juga potesi wisata lainnya, seperti air terjun yang jaraknya tidak begitu jauh, yaitu air terjun Curug Kembar serta keindahan wisata alamnya, yaitu hutan pinus, dan area camping.

Lokasi Desa Batulayang pada sebelah utara berbatasan dengan Desa Jogjogan, sebelah timur berbatasan dengan Desa Tugu Utara, sebelah selatan berbatasan dengan Jalan Raya Puncak, dan sebelah barat berbatasan dengan Kelurahan Cisarua. Jumlah wisatawan yang dating ke Desa Wisata Batulayang meningkat setiap tahunnya, Hal ini membuktikan daya tarik wisata di desa ini semakin dikenal, baik wisiatawan domestik maupun mancanegara.

Berdasarkan hal yang telah diuraikan sebelumnya, dapat diketahui bahwa desa wisata memiliki potesi untuk mendapatkan keuntungan dari segi ekonomi, baik bagi pemerintah maupun warga sekitar. Adapun tujuan dari penelitian ini ingin mengetahui dampak positif terhadap kesejahteraan dan pertumbuhan ekonomi dalam penerapan konsep desa wisata di Desa Batulayang. Hasil penelitian diharapkan mampu memberikan informasi bagi pihak pengelola agar dapat memperbaiki kekurangan yang ada.

\subsection{Desa Wisata}

Nuryanti, Wiendu dalam Priyanto dan Dyah Safitri (2015:78) menyebutkan bahwa desa wisata merupakan bentuk perpaduan antara atraksi, akomodasi, dan fasilitas pendukung yang dibuat dalam suatu struktur kehidupan masyarakat untuk menyatu dengan tata cara tradisi yang berlaku bagi wisatawan yang datang. Persyaratan yang harus dipenuhi antara lain: 
(a) Aksesibilitas yang baik, memudahkan para wisatawan untuk menggunakan berbagai jenis alat transportasi dengan mudah.

(b) Memiliki obyek-obyek menarik berupa alam, seni budaya, legenda, makanan lokal, dan sebagainya untuk dikembangkan sebagai daya tarik wisata.

(c) Masyarakat dan aparat desanya menerima dan memberikan dukungan yang tinggi terhadap desa wisata serta para wisatawan yang datang ke desanya.

(d) Memberikan keamanan di desa tersebut terjamin.

(e) ketersediaan akomodasi, telekomunikasi, dan tenaga kerja yang memadai.

(f) Memiliki iklim sejuk atau dingin.

Lane menyetujui jika dalam Made Antara dan Sukma Arida (2015:12) mengemukakan bahwa ada kesulitan saat menentukan batasan atau definisi pariwisata perdesaan karena beberapa faktor, antara lain:

(a) Daerah pedesaan tersebut masih sukar ditentukan batasannya,

(b) Tidak hanya pedesaan yang bisa di katakan sebagai desa wisata akan tetapi daerah perkotaan juga bisa di sebut desa wisata jika letaknya di daerah pedesaan,

(c) Menurut sejarah, wisatawan kota inilah yang sangat sibuk dengan aktivitasnya sehingga mereka tidak merasakan suasana pedesaan lagi dan wisatawan lah yang menciptakan bentuk pariwisata pedesaan yang dikembangkan masing-masing daerah untuk memenuhi kebutuhan ekonomi masyarakat lokal.

(d) Daerah pedesaan itu sendiri mengalami perubahan yang sangat kompleks akibat pengaruh dari pasar global, komunikasi, dan telekomunikasi, dan

(e) Pariwisata perdesaan terdiri dari berbagai macam aktivitas yaitu, pariwisata alam, jalan-jalan, mendaki, berkuda, petualangan, olah raga dan kesehatan, berburu, belajar tentang kebudayaan daerah setempat.

Selanjutnya juga disebutkan bahwa pariwisata perdesaan harus memperhatikan halhal seperti:

(a) Lokasinya harus di daerah pedesaan guna menciptakan suasana yang diinginkan wisatawan.

(b) Suasana pedesaan memiliki ciri khusus, yaitu usaha kecil, ruang terbuka, berhubungan dengan alam dan keaslian kegiatan masyarakat tradisional.

(c) Bersifat tradisional untuk segala hal, dan berkembang secara perlahan dan berhubungan dengan masyarakat lokal.

(d) Skala ukur pedesaan yang baik dalam bentuk bangunan maupun pengaturan harus selalu dalam skala kecil.

(e) Penyajikan bentuk yang komplek dari lingkungan pedesaan, ekonomi, sejarah, dan lokasinya.

Keberhasilan pariwisata perdesaan dipengaruhi oleh intensitas kegiatan, lokasinya, manajemen, dan daya dukungan dari masyarakat lokal dan harus sesuai dengan keinginan masyarakat lokal.

Inskeep mengungkapkan dalam Ade Jafar Sidiq dan Risna Resnawaty (2017:39) bahwa desa wisata merupakan bentuk pariwisata dari sekelompok kecil wisatawan yang tinggal di dalam atau di dekat kehidupan tradisional atau di desa-desa terpencil dan mempelajari kehidupan desa dan lingkungan lokal.

\section{Pertumbuhan Ekonomi}

Dampak positif pariwisata terhadap perekonomian menurut IUOTO (International Union of Official Travel Organization) yang dikutip Suwena (2017) sebagai berikut:

(a) Foreign Exchange Earnings 
Pengeluaran sektor pariwisata akan menyebabkan perekonomian masyarakat lokal menggeliat dan menjadi stimulus berinvestasi dan menyebabkan sektor keuangan bertumbuh seiring bertumbuhnya sektor ekonomi lainnya. Pengalaman di beberapa negara bahwa kedatangan wisatawan ke sebuah destinasi wisata juga menyebabkan bertumbuhnya bisnis valuta asing untuk memberikan pelayanan dan kemudahan bagi wisatawan selama mereka berwisata.

(b) Contributions To Government Revenues

Kontribusi pariwisata terhadap pendapatan pemerintah dapat diuraikan menjadi dua, yakni: kontribusi langsung dan tidak langsung. Kontribusi langsung berasal dari pajak pendapatan yang dipungut dari para pekerja pariwisata dan pelaku bisnis pariwisata pada kawasan wisata yang diterima langsung oleh dinas pendapatan suatu destinasi. Sedangkan kontribusi tidak langsung pariwisata terhadap pendapatan pemerintah berasal dari pajak atau bea cukai barang-barang yang di import dan pajak yang dikenakan kepada wisatawan yang berkunjung.

(c) Employment Generation

Pada beberapa negara yang telah mengembangkan sektor pariwisata, terbukti bahwa sektor pariwisata secara internasional berkontribusi nyata terhadap penciptaan peluang kerja, penciptaan usaha-usaha terkait pariwisata seperti usaha akomodasi, restoran, klub, taxi, dan usaha kerajinan seni souvenir.

(d) Infrastructure Development

Berkembangnya sektor pariwisata juga dapat mendorong pemerintah lokal untuk menyediakan infrastruktur yang lebih baik, penyediaan air bersih, listrik, telekomunikasi, transportasi umum dan fasilitas pendukung lainnya sebagai konsekuensi logis dan kesemuanya itu dapat meningkatkan kualitas hidup baik wisatawan dan juga masyarakat local itu sendiri sebagai tuan rumah.

(e) Development of Local Economies

Pendapatan sektor pariwisata acapkali digunakan untuk mengukur nilai ekonomi pada suatu kawasan wisata. Sementara ada beberapa pendapatan lokal sangat sulit untuk dihitung karena tidak semua pengeluaran wisatawan dapat diketahui dengan jelas seperti misalnya penghasilan para pekerja informal seperti sopir taksi tidak resmi, pramuwisata tidak resmi, dan lain sebagainya.

2. Pariwisata dan Pertumbuhan Ekonomi

Bisa diuraikan hasil penelitian Nizar dalam Yakup, 2019, yang menguji hubungan pariwisata dengan pertumbuhan ekonomi mengacu pada pertumbuhan dan hubungan perdagangan. Pola kausalitas ini berdasarkan pada tiga hipotesisyang berbeda, antara lain :

(a) Hipotesis pertumbuhan ekonomi yang ditopang oleh pariwisata (Tourism-Led Economic Growth Hypothesis). Hiptosesis Hal ini mengaggap bahwa ekspansi disektor pariwisata mampu mempengaruhi pertumbuhan ekonomi suatu negara.

(b) Hipotesis pertumbuhan pariwisata yang digerakan oleh pertumbuhan ekonomi (Economic-Driven Tourism Growth Hypothesis). Hipotesis ini menganggap pertumbuhan ekonomi mampu mempengaruhi perkembangan/ekspansi sektor pariwisata.

(c) Hipotesis kualitas timbal balik (Reciprocal Causal Hypothesis), menyatakan adanya hubungan kausalitas antara pertumbuhan ekonomi dan perkembangan pariwisata bersifat dua arah (bidirectional). Maka dorongan pada kedua variabel ini akan saling mempengaruhi.

Pembuktian antara ekspansi pariwisata dengan pertumbuhan ekonomi sangat penting. Hal ini dapat memberikan manfaat dalam membuat keputusan kebijakan yang relevan. Tetapi bila tidak ditemukan adanya hubungan kausal antara ekspansi pariwisata 
dengan pertumbuhan ekonomi, maka hasil tersebut dapat dijadikan indikasi untuk melihat efektivitas dari sebuah strategi pariwisata.

\section{Metode Penelitian}

Penelitian ini dilaksanakan di Desa Wisata Batulayang yang berlokasi di Jalan Sultan Hasanudin Kap. Pasir Manggis Batukasur RT/RW 006/004, Desa Batulayang Keamatan Cisarua, Kabupaten Bogor, Jawa Barat. Pada penelitian ini penulis menggunakan, non probability sampling. Menurut Sugiyono (2010, h.66), non probability sampling adalah teknik pengambilan sampel yang tidak memberi peluang atau kesempatan yang sama bagi setiap unsur atau anggota populasi untuk dipilih menjadi sampel.

Pada penelitian ini, sampel yang digunakan hanya penduduk yang tinggal di desa Batulayang. Teknik sampling yang digunakan yaitu sampling incidental, yaitu teknik penentuan sampel berdasarkan kebetulan, yaitu siapa saja yang secara kebetulan atau incidental bertemu dengan peneliti dapat digunakan sebagai sampel, bila dipandang orang yang kebetulan ditemui cocok sebagai sumber data (Sugiyono, 2010, h.67).

Penelitian ini juga menggunakan alat bantu skala Guttman dan Likert. Menurut Siregar (2013, h,29), skala Guttman ialah skala yang digunakan untuk jawaban yang bersikap tegas (jelas). Data yang diperoleh dapat berupa data interval atau rasio dikotomi (dua alternatif). Pilihan jawaban pada jenis skala ini hanya terdiri dari dua pilihan, seperti setuju-tidak setuju, ya-tidak, yakin-tidak yakin, sedangkan untuk jawaban responden angka tertinggi 1 (satu) dan angka terendah 0 (nol).

Skala likert dimodifikasi menjadi empat alternatif pilihan jawaban dengan menghilangkan kategori ragu-ragu. Hal ini dilakukan untuk mencegah responden netral atau tidak memilih sehingga mengurangi banyaknya informasi yang dapat dijaring dari responden. Menurut Arikunto (2009) peneliti berpendapat bahwa ada kelemahan dengan lima alternatif yang ada ditengah (karena dirasa aman dan paling mudah, karena responden tidak perlu berpikir) dan alasan tersebut memang benar adanya. Maka dari teori tersebut, dalam pembuatan kuesioner peneliti akan menggunakan skala likert sebagai berikut:

$\begin{array}{ll}\text { Sangat Tidak Setuju } & =\text { Skor } 1 \\ \text { Tidak Setuju } & =\text { Skor } 2 \\ \text { Setuju } & =\text { Skor } 3 \\ \text { Sangat Setuju = Skor } 4\end{array}$

Dalam penelitian ini menggunakan metode analisis diagram kartesius, diagram kartesius merupakan suatu bangun yang dibagi atas empat bagian yang dibatasi oleh dua buah garis yang berpotongan tegak lurus pada titik. Titik $(\mathrm{X}, \mathrm{Y})$ dimana $\mathrm{X}$ merupakan ratarata dari skor harapan seluruh faktor yang mempengaruhi keputusan wisatawan dalam berkunjung, sedangkan $\mathrm{Y}$ adalah rata-rata skor kenyataan seluruh faktor yang mempengaruhi keputusan wisatawan dalam melakukan kunjungan. Biasanya, diagram kartesius digunakan untuk mengukur variabel-variabel yang digunakan.

Populasi dalam penelitian ini adalah penduduk yang mengelola atau mencari nafkah yang ada di Desa Batulayang. Sampel menurut Heir et al., dalam Yoepitasari, 2018, dapat memegang peranan penting dalam estimasi dalam dan interprestasi hasil penelitian maka ukuran sampel yang ideal dan respresentatif tergantung pada jumlah indikator pertanyaan yang digunakan kemudian dikalikan 5 ( $\mathrm{n} \times 5$ ) observed variable (indikator) sampai dengan $\mathrm{n}$ x 10 observed variable (indikator). Dalam penelitian ini jumlah item adalah 15 pertanyaan yang digunakan untuk mengukur 5 variabel, sehingga jumlah responden yang digunakan adalah 15 X $5=75$, oleh karena itu pada penelitian ini mengambil sampel sebanyak 75 orang, maka kuesioner yang akan disebar sebanyak 75 responden sebagai perwakilan dari jumlah populasi. 


\section{Pembahasan}

Dari penyebaran kuesioner profil responden dapat dirincikan menjadi berbagai karakteristik yang berbeda-beda yaitu jenis kelamin, umur, pekerjaan, pendapatan sebagai berikut :

Tabel 1. Jenis Kelamin Responden

\begin{tabular}{|l|l|l|}
\hline Jenis Kelamin & Frekuensi & Presentase (\%) \\
\hline Laki-Laki & 46 & $61 \%$ \\
\hline Perempuan & 29 & $39 \%$ \\
\hline Jumlah & 75 & $100 \%$ \\
\hline
\end{tabular}

Sumber : Hasil Olah Data Penulis 2020

Berdasarkan tabel di atas, dapat diketahui bahwa sebagian besar responden berjenis kelamin laki-laki, yaitu sebesar $61 \%$ dan sisanya berjenis kelamin perempuan, yaitu sebesar $39 \%$.

Tabel 2. Umur Responden

\begin{tabular}{|l|l|l|}
\hline Umur & Frekuensi & Presentase $(\%)$ \\
\hline$<25$ Tahun & 22 & $29 \%$ \\
\hline 26-35 Tahun & 19 & $25 \%$ \\
\hline 36-45 Tahun & 17 & $23 \%$ \\
\hline$>46$ Tahun & 17 & $23 \%$ \\
\hline Total & 75 & $100 \%$ \\
\hline
\end{tabular}

Hasil Olah Data Penulis 2020

Berdasarkan tabel di atas, dapat diketahui bahwa sebagian besar responden merupakan penduduk dengan rentang umur $<25$ Tahun, yaitu sebesar 29\%, sedangkan penduduk dengan rentang umur 26 - 35 Tahun yaitu sebesar $25 \%$, penduduk dengan umur 36 - 45 Tahun sebesar 23\%, dan penduduk dengan rentang umur 46 Tahun sebesar $23 \%$.

Tabel 3. Pekerjaan Responden

\begin{tabular}{|l|l|l|}
\hline Pekerjaan & Frekuesnsi & Presentase (\%) \\
\hline Petani & 12 & $16 \%$ \\
\hline Peternak & 14 & $19 \%$ \\
\hline Pedagang dan Pengusaha & 9 & $12 \%$ \\
\hline Pemilik Home Stay & 24 & $32 \%$ \\
\hline Sopir Angkutan \& Ojek & 9 & $12 \%$ \\
\hline Guru Sekolah dan Guru Ngaji & 7 & $9 \%$ \\
\hline Jumlah & 75 & $100 \%$ \\
\hline
\end{tabular}

Sumber : Hasil Olah Data Penulis 2020

Berdasarkan tabel di atas, dapat diketahui bahwa sebagian besar responden merupakan warga yang bekerja sebagai petani, yaitu sebesar $16 \%$, sedangkan penduduk dengan pekerjaannya peternak yaitu sebesar $19 \%$, penduduk yang merupakan pedagang dan pengusaha sebesar $12 \%$, penduduk dengan pekerjaan sebagai pemilik homestay sebesar 32\%, penduduk dengan pekerjaan sopir angkutan dan ojek sebesar 12\%, dan penduduk yang bekerja sebagai guru sekolah dan guru ngaji sebesar $9 \%$.

Tabel 4. Pendapatan Responden

\begin{tabular}{|l|l|l|}
\hline Pendapatan & Frekuensi & Presentase (\%) \\
\hline Rp. 0 - Rp. 1.800 .000 & 13 & $17 \%$ \\
\hline Rp. $>1.800 .000$ - Rp. 2.800 .000 & 21 & $28 \%$ \\
\hline Rp. $>2.800 .000$ - Rp. 3.800.000 & 25 & $34 \%$ \\
\hline
\end{tabular}




\begin{tabular}{|l|l|l|}
\hline Pendapatan & Frekuensi & Presentase (\%) \\
\hline Rp. $>3.800 .000$ & 15 & $20 \%$ \\
\hline Jumlah & 75 & $100 \%$ \\
\hline
\end{tabular}

Sumber : Hasil Olah Data Penulis 2020

Berdasarkan data diatas, dapat dilihat besar pendapatan penduduk Desa Batulayang berkisaran diantara Rp. 0 - Rp. 1.800 .000 sebesar 18\%, penduduk penghasilan sebesar $>1.800 .000$ - Rp. 2.800.000 28\%, penduduk penghasilan sebesar Rp. >2.800.000 - Rp. 3.800.000 34\%, dan penduduk penghasilan sebesar Rp. >3.800.000 20\%.

Diagram kartesius digunakan untuk mengetahui titik ordinal serta mengetahui faktor yang termasuk kuadran I, II, III, atau IV. Faktor yang dimaksud antara lain Contributions to Government Revenues, Employment Generation, Infrastructure Development, dan Development of Local Economies.

Tabel 5. Dampak positif pariwisata terhadap perekonomian

\begin{tabular}{|l|l|l|}
\hline $\begin{array}{c}\text { Dampak positif pariwisata terhadap } \\
\text { perekonomian }\end{array}$ & Harapan & Kenyataan \\
\hline Foreign Exchange Earnings & 3,47 & 3,13 \\
\hline $\begin{array}{l}\text { Contributions to Government } \\
\text { Revenues }\end{array}$ & 3,32 & 3,29 \\
\hline Employment Generation & 3,35 & 3,26 \\
\hline Infrastructure Development & 3,21 & 3,32 \\
\hline Development of Local Economies & 3,22 & 3,19 \\
\hline Total & 16,42 & 16,23 \\
\hline
\end{tabular}

Sumber : Hasil Olah Data Penulis 2020

Dalam penelitian ini, penulis menetapkan 4 kelas interval. Rumus yang digunakan menurut Sudjana (2001, p.47) adalah sebagai berikut :

Deskripsi:

$$
P=\frac{\text { Range }}{\text { The Number of Classes }}
$$

$\mathrm{P} \quad=$ Panjang kelas interval yang

Kisaran $\quad=$ Data terbesar - Data terkecil

Maka perhitungan intervalnya adalah : $\quad \mathrm{p}=\frac{4-1}{4}$

$$
\mathrm{P}=0,75 \rightarrow 0,8
$$

Berdasarkan perhitungan, diputuskan bahwa panjang kelas interval 0,8. Oleh karena itu, interval adalah sebagai berikut :

Tabel 6. Interval Skala Likert

\begin{tabular}{|l|l|}
\hline Assessment Category & Interval \\
\hline \hline Sangat Tidak setuju & $1,00-1,80$ \\
\hline Tidak setuju & $1,81-2,61$ \\
\hline Setuju & $2,62-3,42$ \\
\hline Sangat setuju & $3,43-4,23$ \\
\hline
\end{tabular}

Hasil Olah Data Penulis 2020

Untuk opini dampak positif ekonomi di desa Batulayang berdasarkan skala likert sebagai berikut : 
Tabel 7. Nilai Total Variabel Berdasarkan Tingkat Harapan dan Kenyataan

\begin{tabular}{||l||l|l|l|l|}
\hline $\begin{array}{c}\text { Dampak positif } \\
\text { pariwisata terhadap } \\
\text { perekonomian }\end{array}$ & Harapan & Keterangan & Kenyataan & Keterangan \\
\hline $\begin{array}{c}\text { Foreign Exchange } \\
\text { Earnings }\end{array}$ & 3,47 & Sangat Setuju & 3,13 & Setuju \\
\hline $\begin{array}{c}\text { Contributions } \\
\text { Government } \\
\text { Revenues }\end{array}$ & 3,32 & Setuju & 3,29 & Setuju \\
\hline Employment Generation & 3,35 & Setuju & 3,26 & Setuju \\
\hline $\begin{array}{c}\text { Infrastructure } \\
\text { Development }\end{array}$ & 3,21 & Setuju & 3,32 & Setuju \\
\hline $\begin{array}{c}\text { Development of Local } \\
\text { Economies }\end{array}$ & 3,22 & Setuju & 3,19 & Setuju \\
\hline
\end{tabular}

Hasil Olah Data Penulis 2020

Berdasarkan skala interval likert, opini penduduk Desa Batulayang memiliki 5 dimensi dan semua dimensi disetujui. Pada penelitian yang dilakukan terhadap dimensi Exchange melakukan transaksi Earnings pada harapan memiliki hasil yang sangat setuju dimana penduduk desa dapat pembayaran dengan menggunakan mata uang asing dan adanya tempat penukaran mata uang asing yang dikelola oleh penduduk sekitar.

Sedangkan opini dampak positif ekonomi di Desa Batulayang setelah diolah kedalam diagram kartesius menghasilkan hasil sebagai berikut :

Gambar 1. Hasil Diagram Kartesius

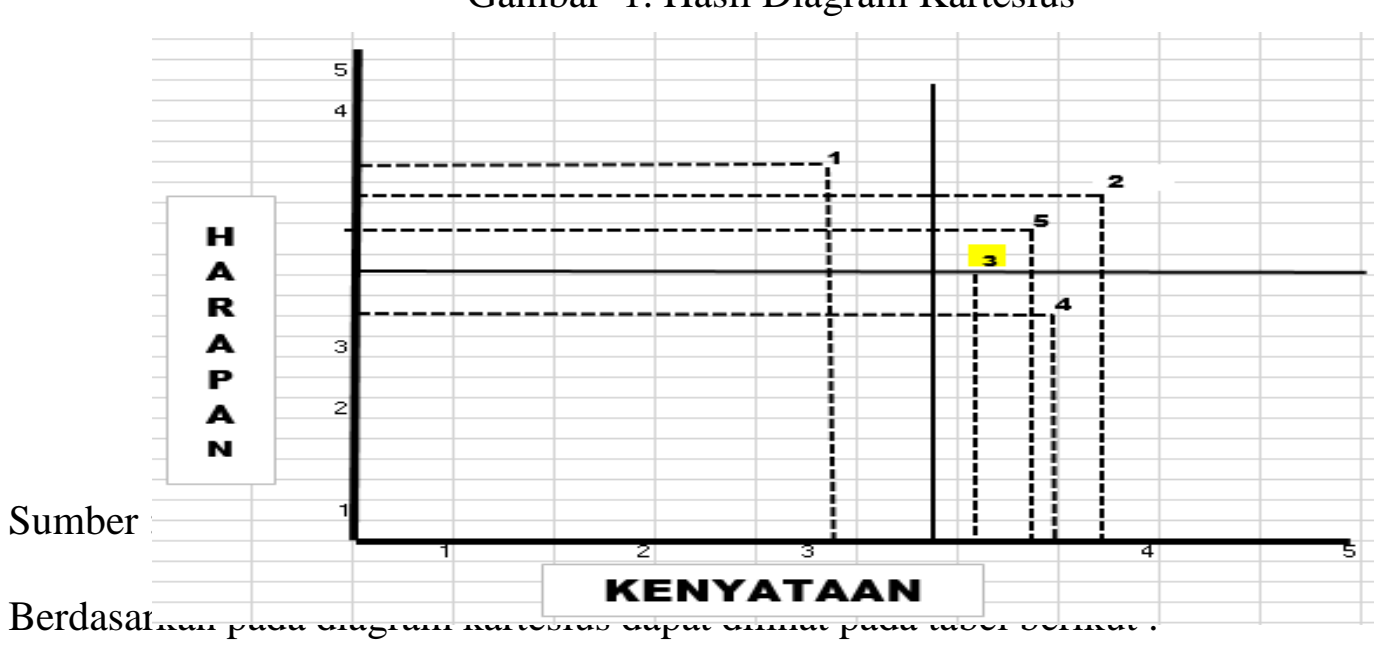

Tabel 8 Hasil Kuadran

\begin{tabular}{|l|c|}
\hline Kuadran & $\begin{array}{c}\text { Dampak positif pariwisata terhadap } \\
\text { perekonomian }\end{array}$ \\
\hline Kuadran I & - Foreign Exchange Earnings \\
\hline \multirow{3}{*}{ Kuadaran II } & - Contributions To Government \\
& Revenues \\
& - Employment Generation \\
&
\end{tabular}




\begin{tabular}{|l|l|}
\hline & \multicolumn{1}{|c|}{ Economies } \\
\hline Kuadran III & - \\
\hline Kuadran IV & $\bullet \quad$ Infrastructure Development \\
\hline
\end{tabular}

Sumber : Hasil Olah Data Penulis 2020

\section{- $\quad$ Kuadran I}

Pada kuadran I terdapat 1 dimensi, yakni Foreign Exchange Earnings dengan harapan sangat setuju dan kenyataan setuju. Berarti dimensi tersebut memiliki prioritas yang tinggi dan perlu diadakan, sebab jika terdapat tamu dari luar negeri dan mengalami kekurangan financial dalam mata uang rupiah maka wisatawan asing dapat menggunakan mata uang dari negaranya secara cash atau dengan cara menggunakan bank. Sehingga mempermudah kedua belah pihak.

- $\quad$ Kuadran II

Pada kuadran II terdapat Contributions to Government Revenues, Employment Generation, dan Development of Local Economies dengan kenyataan dan harapan setuju atau dengan kata lain sudah sesuai. Artinya pada dimensi tersebut dianggap penting dan harus dipertahankan.

\section{- $\quad$ Kuadran III}

Pada kuadran III ini tidak ada, dengan kata lain pada kuadran ini tidak terlalu berpengaruh pada pertumbuhan ekonomi.

- Kuadran IV

Pada kuadran IV terdapat Infrastructure Development. Pada kuadran ini dianggap kurang penting. Infrastructure Development pada faktor ini adalah berupa jaringan internet, dikarenakan para wisatawan akan sibuk dengan kegiatan yang diadakan pada paket wisata yang disediakan oleh pengelola Desa Wisata Batulayang, sehingga wisatawan akan menggunakan smartphone pada saat sebelum tidur. Namun untuk sinyal, dan listrik sudah tersedia dan dapat diakses, serta untuk akses jalan sudah dapat dilalui dengan kendaraan pribadi.

\section{Kesimpulan}

\subsection{Kesimpulan}

Berdasarkan hasil pengolahan data dan pembahasan pada penelitian ini, maka dapat disimpulkan sebagai berikut:

- Penduduk sekitar Desa Batulayang, mayoritas profesi yang dilakukan ialah memasarkan rumahnya sebagai homestay yang menjadikan sumber mata pencaharian utama. Serta rata-rata pendapat yang di terima oleh warga desa Batulayang ialah kisaran Rp. >2.800.000 - Rp. 3.800.000.

- Desa wisata Batulayang merupakan desa wisata yang cocok bagi para wisatawan, jarak yang tidak terlalu jauh serta untuk menikmati kehidupan perdesaan di sana.

- Berdasarkan skala likert Foreign Exchange Earnings dengan harapan sangat setuju dan kenyataan setuju, Contributions to Government Revenues, Employment Generation, dan Development of Local Economies dengan kenyataan dan harapan setuju, Infrastructure Development dianggap tidak terlalu penting.

- Dengan adanya penerapan konsep desa wisata menjadikan terbantunya perekonomian masyarakat melalui penginapan, warung-warung kecil, warung makan, transportasi, pertanian, dan peternakan. Selain itu desa Batulayang dari tahun ke tahun selalu mendapatkan penghargaan dari tingkat lokal sampai nasional tentang kebersihan dan keasrian lingkungan dan di kenal banyak orang. Fasilitas yang ada pun cukup lengkap seperti masjid, tempat parkir, toilet, homestay rumah penduduk, dan pondokan. 


\subsection{Saran}

Berdasarkan hasil dari penelitian yang telah dilakukan, penulis memberikan beberapa saran yang dapat dijadikan bahan pertimbangan:

- Pengelola desa wisata dapat bekerjasama dalam membuat aplikasi untuk memudahkan dalam hal informasi serta untuk melakukan pemesanan homestay agar lebih memudahkan wisatawan.

- Membuat metode pembayaran dengan cara sistem online agar terdapat pencatatan dan mengurangi kesalahan human error serta memudahkan wisatawan asing untuk melakukan pembayaran.

- Perlu adanya kelibatan pemerintah serta pihak swasta untuk menambah objek wisata buatan agar menambah terbukanya lowongan pekerjaan bagi warga sekitar.

- Perlu ditambahkan lahan untuk pakir kendaraan agar tidak mengalami kesulitan ketika wisatawan datang

- Diperlukan adanya pihak yang melakukan penilaian untuk standar homestay.

- Diperlukan perbaikan akses jalan menuju Desa Batulayang.

Referensi

Antara, Made dan Sukma Arida. (2015). Panduan Pengelolaan Desa Wisata Berbasis Potensi Lokal. Universitas Udayana Bali

Arikunto, S. (2009). Prosedur Penelitian Suatu Pendekatan Praktik Edisi Revisi 6. Jakarta: Rineka Cipta.

Dewi, Liliana. 2019. Tourism Village Development In Bogor District. Sekolah Tinggi Pariwisata Bogor.

Hermawan, Hary dan erlangga brahmanto (2017). GEOWISATA (Perencanaan Pariwisata Berbasis Konsevasi).

Lubis, Ucok Pargaulan (2018). Faktor-Faktor yang Mempengaruhi Wisatawan dalam Berkunjung Ke Wisata Swimbath (Desa Bahapal, Kecamatan Bandar Huluan, Kabupaten Simalungu) Universitas Sumatera Utara.

Muljadi, A. (2009). Kepariwisataan dan Perjalanan. Jakarta: PT Raja Grafindo Persada.

Natalia, Dessy (2019). Pengaruh Daya Tarik Wisata Terhadap Minat Kunjungan Wisatawan di Fun Park Water Boom Permata. Jakarta : Universitas Bunda Mulia.

Nizar, Yakub (2019). Pengaruh Pariwisata Terhadap Pertumbuhan Ekonomi di Indonesia. Surabaya : Universitas Airlangga Surabaya.

Priyanto, Dyah Safitri (2015). Pengembangan Potensi Desa Wisata Berbasis Budaya Tinjauan Terhadap Desa Wisata Di Jawa Tengah. Universitas Indonesia.

Republik Indonesia (2009). Undang-Undang No. 10 Tahun 2009 tentang Kepariwisataan. Lembaran Negara RI Tahun 2009, No. 11. Sekretariat Negara. Jakarta.

Sidiq, Ade Jafar dan Risna Resnawaty (2017). Pengembangan Desa Wisata Berbasis Partisipasi Masyarakat Lokal Di Desa Wisata Linggarjati Kuningan, Jawa Barat.

Siregar, S. (2013). Metode Penelitian Kuantitatif Dilengkapi Perbandingan Perhitungan Manual \& SPSS. Jakarta: Kencana Prenada Media Group.

Sugiyono. (2010). Statistika Untuk Penelitian. Bandung: CV. Alfabeta.

Suwena, I. K., \& Widyatmaja, I. G. (2017). Pengetahuan Dasar Ilmu Pariwisata. Denpasar: Pustaka Larasan.

Yakup, (2019). Pengaruh Sektor Pariwisata Terhadap Pertumbuhan Ekonomi di Indonesia, Tesis. Fakultas Ekonomi dan Bisnis. Universitas Airlangga : 2019

Yoepitasari, H. A., (2018). Analisis Pengaruh Kualitas Produk, Promosi dan Desain Produk Terhadap Keputusan Pembelian Dengan Citra Merek Sebagai Variabel Intervening. Jurnal Studi Manajemen Organisasi 15 (2018) Juni 55-69. http://ejournal.undip.ac.id/index.php/smo. 